\title{
Histopathology of COVID-19 pneumonia in two non-oncological, non-hospitalised cases as a reliable diagnostic benchmark
}

\author{
Roberto Scendoni ${ }^{1 *} \mathbb{D}$, Francesca Marchesani ${ }^{2}$, Nunzia Cannovo ${ }^{3}$, Piergiorgio Fedeli ${ }^{3}$ and Mariano Cingolani ${ }^{1}$
}

\begin{abstract}
In lung cancer patients infected with COVID-19, pathological features are not easy to distinguish. This report presents detailed histopathological findings in two non-neoplastic subjects whose out-of-hospital deaths were caused by COVID-19 infection. These 'pure' cases differ in the time of presentation of symptoms, the phase of lung anatomopathological patterns (acute lung injury versus diffuse alveolar damage) and the mechanism of death. The results provide a valid diagnostic benchmark for evaluating the evolution of COVID-19 pneumonia.
\end{abstract}

Keywords: COVID-19 pneumonia, Histopathology, Diffuse alveolar damage, Oncological patient, Lung cancer

\section{Introduction}

Although several months have passed since the epidemic spread of the virus, current information on the pathological characteristics of deaths caused by COVID-19 is often variable [1], and in neoplastic patients, especially those with lung cancer, these characteristics can overlap or be difficult to attribute correctly.

Authors [2] have recently considered lung disease in hospitalised patients with lung cancer who have also been infected with COVID-19. However, what is the borderline between cancer-related lung disease (whether the subject is undergoing therapy or not) and lung disease linked to COVID-19? It has been documented that oncological patients who develop an acute respiratory distress syndrome (ARDS) have a significantly higher risk of death compared with those who develop ARDS without cancer, and this increased risk appears to be correlated with the increased severity of illness at presentation [3].

In addition, can the presence of other infections besides COVID-19 be entirely ruled out? Studies have shown that

\footnotetext{
* Correspondence: r.scendoni@unimc.it

${ }^{1}$ Institute of Legal Medicine, Department of Law, University of Macerata, Piaggia dell'Università, 2, 62100 Macerata, Italy

Full list of author information is available at the end of the article
}

many infectious agents are responsible for approximately $90 \%$ of all primary and secondary causes of ARDS in the cancer setting [4]. Furthermore, ARDS is a major cause of postoperative respiratory failure, with mortality rates reaching $40 \%$ in the general population. Mortality rates in the cancer population vary widely, depending on the type of cancer, and thoracic surgeries carry the highest operational risk of lung damage [5]. Plus, the case fatality rate is significantly higher for those with an underlying concomitant disease, such as cardiovascular disease, diabetes, or chronic respiratory disease. Lung cancer represents a specific scenario of cumulative risk factors for COVID-19 complications [6], although the clinical course for these patients is still not well defined.

In order to contribute to the body of knowledge in this area, we have presented the detailed pathological findings in two cases of non-neoplastic subjects whose outof-hospital deaths were caused by COVID-19 infection. They differed in the time of presentation of symptoms and consequently manifested different anatomopathological patterns, the first defining an early phase of the infection and the second showing a later stage. It is hoped that these findings will contribute to a better description of the pulmonary pathology of Sars-Cov-2 and also 
improve treatment choices for all COVID-19 cases including cancer patients, in line with proposals by other authors.

\section{Cases and methods}

Anamnestic data and the circumstances of the deaths of the subjects, who both died at home, were collected. Before autopsy an oropharyngeal swab for SARS-CoV-2 viral RNA was performed, which tested positive in both cases.

Case 1: a 44-year-old man affected by polymyositis without pharmacological treatment, who for 3 days presented fever, marked asthenia and dyspnoea, followed by progressive cardiorespiratory insufficiency until exitus.

Case 2: a 62-year-old woman suffering from hypertension (not undergoing pharmacological treatment), autoimmune hypothyroidism and type 2 diabetes treated with oral hypoglycaemics, deceased after 8-9 days of high fever and dyspnea.

\section{Methods for histopathology}

Tissue samples were fixed in $4 \%$ formalin, processed, embedded in paraffin and then cut with a microtome to obtain two sets of thin sections of $8 \mu \mathrm{m}$. The sections obtained were first stretched in distilled water at ambient temperature to eliminate any folds, then in water at $40-45^{\circ} \mathrm{C}$ and finally affixed to the glass slide. One set of sections was then dried in an oven at $37-40{ }^{\circ} \mathrm{C}$ and hematoxylin-eosin (HE) stained. The sections obtained were analyzed by light microscopy; magnified images $(x$ 200 and $\times 400$ ) were acquired of the HE stains with a high-resolution colour microscope camera.

Method for detection of SARS-CoV-2 viral RNA.

A naso-oropharyngeal swab kit for COVID-19 sample collection and transport was used. Using a Real-time PCR thermal cycler, SARS-CoV-2 viral RNA was tested for and detected in both cases.

\section{Results}

Case 1

Autopsy

Macroscopic findings included the presence of extremely warm organs and dense blood. The heart examination revealed thrombosis of the anterior descending coronary artery.

When the thoracic cavity was opened, the lungs failed to collapse and there was a lack of visible exudates in airways. Both lungs had a thicker consistency (case 2 more than case 1 ), were compact, congested and edematous (case 1 more than case 2).

\section{Microscopic findings}

Thickening of the alveolar septa because of edema, hemorrhage and inflammatory cell infiltrations in the interalveolar septa (Fig. 1a). Mild presence of type II hyperplastic pneumocytes and fibroblasts in the alveolar septa (Fig. 1)b.

\section{Case 2}

\section{Autopsy}

As in case 1, the organs were extremely warm and the blood was particularly dense. Macroscopic examination revealed intracardiac thrombosis and bilateral massive thromboembolism. Both lungs were markedly edematous and compact.

\section{Microscopic findings}

Myocardial vascular microthrombosis (Fig. 2). Diffuse alveolar damage (DAD) with organised hyaline membranes, sometimes with fibrotic aspects; presence of scattered large protein globules (Fig. 3). Expanded alveolar septa with inflammatory infiltrate (prevalently of lymphocytes and macrophages), fibroblasts and type II hyperplastic pneumocytes.

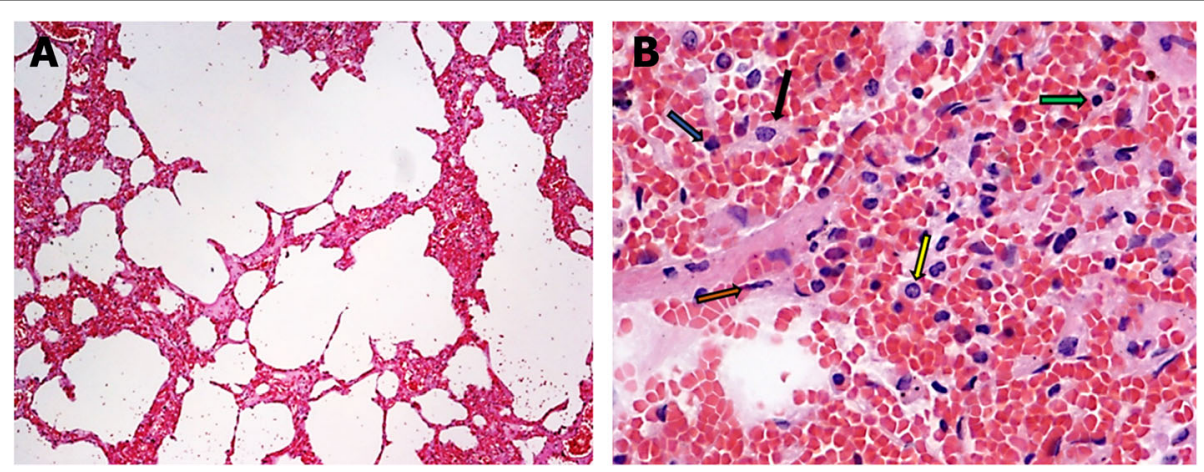

Fig. 1 Histological changes in case 1. a Exudative phase of acute interstitial pneumonia (hematoxylin and eosin stain, $\times 100$ ). $\mathbf{b}$ Detail of an alveolar septum with edema, hemorrhage and inflammatory cell infiltrations (green arrow: lymphocyte; yellow arrow: macrophage; brown arrow: fibroblast; blue arrow: polymorphonuclear leukocyte; black arrow: type II hyperplastic pneumocyte) (hematoxylin and eosin stain, $\times 400$ ) 


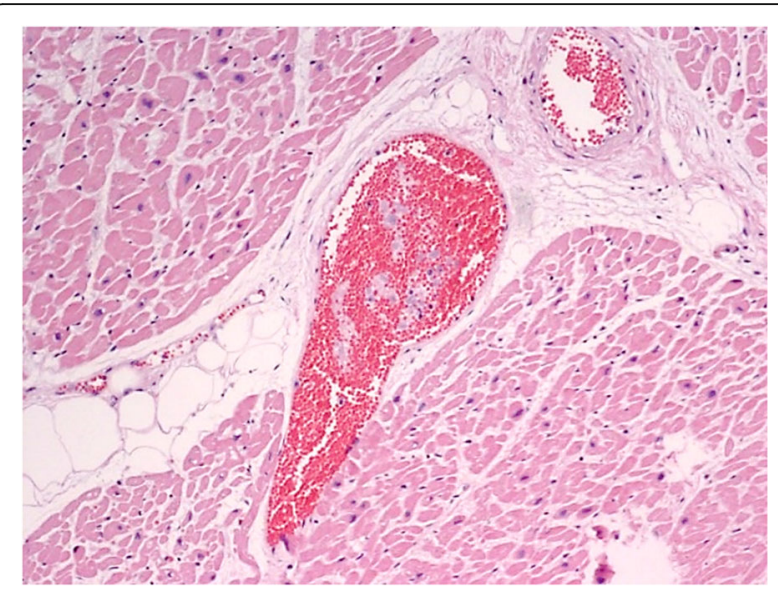

Fig. 2 Myocardial vascular microthrombosis (hematoxylin and eosin stain, $\times 200$ )

\section{Discussion}

The two cases presented different stages of pulmonary morbidity linked to COVID-19. Respiratory viruses can cause a wide spectrum of pulmonary diseases [7]: in case 1 , the exudative phase of acute interstitial pneumonia was observed indicating acute lung injury (ALI), while case 2 exhibited a later phase of DAD, with the development of ARDS. The histological findings correlated with the period of manifestation of symptoms: in case 1, the subject met with an early death because of the onset of acute coronary syndrome due to thrombosis of the anterior descending artery related to COVID-19 infection [8]; in case 2, the continuation of the infection caused a pulmonary thromboembolism and, in the lungs, a proliferative phase

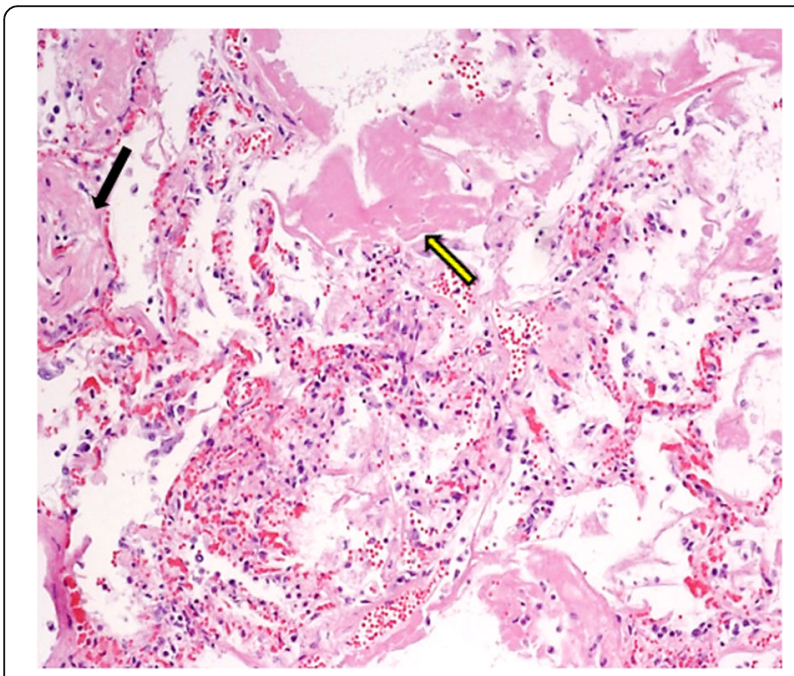

Fig. 3 DAD pattern with hyaline membrane and moderate fibrotic organisation (black arrow); presence of scattered large protein globules (yellow arrow). Expanded alveolar septa with inflammatory cells (hematoxylin and eosin stain, $\times 200$ ) with prominent hyaline membranes and moderate fibrotic organisation.

Our subjects were non-oncological individuals, free of serious diseases and not hospitalised. Therefore, these are absolutely "pure" cases of COVID-19 infection, with anatomopathological patterns at different stages, not influenced by any other particular conditions.

It has been shown that defective lung architecture from mechanical tumour obstruction or previous lung surgery may also be predisposed to infection. Changes in the anatomy of the airways and lung tissue lead to the alteration of the intra-tumour microenvironment, which can secondarily influence the infiltration of immune cells. An increase in macrophages and inflammation carries an increased risk of cytokine release, which is a precursor to ARDS development [9]. Finally, it must be taken into account that not all patients react in the same way; some authors [10] indicate that the course of COVID-19 is not necessarily ominous in the presence of a compromised immune response and tend to reinforce the emerging therapeutic concepts of a controlled mitigation of the immune cascade following COVID-19 infection.

In the light of this evidence, the following conclusive considerations can be put forward with the aim of providing a better diagnostic-therapeutic framework for cancer patients infected with COVID-19:

a) Patients with severe clinical conditions are unlikely to present histopathological alterations of advanced phases of DAD: damage to such an extent occurs over a considerable period of time, but a patient with a poor clinical prognosis might not survive long enough for the DAD to become completely manifest.

b) An advanced anatomopathological pattern of DAD, however, could be related to the presence of lung cancer and the results of any chemotherapy treatments or surgery.

c) Although immunocompromised patients are more likely to contract the infection, the COVID-19 course is not always predictable in the presence of a compromised immune response.

d) Nosocomial infections other than COVID-19, responsible for the onset of ARDS, should not be ruled out for hospitalised patients.

\footnotetext{
Abbreviations

COVID-19: Corona Virus Disease 2019; ARDS: Acute respiratory distress syndrome; SARS-CoV-2: Severe acute respiratory syndrome coronavirus 2; RNA: Ribonucleic acid; PCR: Polymerase chain reaction; ALl: Acute lung injury; DAD: Diffuse alveolar damage.
}

\section{Acknowledgements}

We would like to thank the Pathological Anatomy Unit of ASUR Marche AV3 for the hematoxylin and eosin staining of tissues. Thanks to Jemma Dunnill for proofreading the manuscript. 


\section{Authors' contributions}

RS acquired the histopathological data retrieved from the autopsies of both subjects and conceived the design of the report; FM analysed the report and encouraged further examination of specific elements; NC and PF researched the recent literature and updated the bibliography; $M C$ supervised all the findings and verified the structure of the manuscript. All authors contributed to the final manuscript.

\section{Funding}

This research received no specific grant from any funding agency in the public, commercial, or not-for-profit sectors.

\section{Availability of data and materials}

The datasets used during the current study are available from the corresponding author on reasonable request.

\section{Ethics approval and consent to participate}

Not applicable.

\section{Consent for publication}

Not applicable.

\section{Competing interests}

The authors declare that they have no competing interests.

\section{Author details}

'Institute of Legal Medicine, Department of Law, University of Macerata, Piaggia dell'Università, 2, 62100 Macerata, Italy. ${ }^{2}$ Pulmonary Unit ASUR Marche AV3, Via Santa Lucia, 62100 Macerata, Italy. Institute of Legal Medicine - School of Law, University of Camerino, Via Andrea D'Accorso n. 16, 62032 Camerino, MC, Italy.

Received: 29 April 2020 Accepted: 4 June 2020

Published online: 09 June 2020

\section{References}

1. Xu Z, Shi L, Wang Y, et al. Pathological findings of COVID-19 associated with acute respiratory distress syndrome. Lancet Respir Med. 2020;8(4):420-2.

2. Tian S, Hu W, Niu L, et al. Pulmonary pathology of early-phase 2019 novel coronavirus (COVID-19) pneumonia in two patients with lung cancer. J Thorac Oncol. 2020. https://doi.org/10.1016/j.tho.2020.02.010.

3. Soubani AO, Shehada E, Chen W, et al. The outcome of cancer patients with acute respiratory distress syndrome. J Crit Care. 2014;29(1):83.e7-183.e12.

4. Azoulay $E$, Lemiale $V$, Mokart $D$, et al. Acute respiratory distress syndrome in patients with malignancies. Intensive Care Med. 2014;40(8):1 106-14.

5. Young AY, Shannon VR. Acute respiratory distress syndrome in cancer patients. Oncologic Critical Care. 2019:557-82.

6. Liang W, Guan W, Chen R, et al. Cancer patients in SARS-CoV-2 infection: a nationwide analysis in China. Lancet Oncol. 2020;21(3):335-7.

7. Gralinski LE, Baric RS. Molecular pathology of emerging coronavirus infections. J Pathol. 2015;235(2):185-95.

8. Clerkin KJ, Fried JA, Raikhelkar J, et al. Coronavirus disease 2019 (COVID-19) and cardiovascular disease. Circulation. 2020. https://doi.org/10.1161/ CIRCULATIONAHA.120.046941.

9. Mehta P, McAuley DF, Brown M, et al. COVID-19: consider cytokine storm syndromes and immunosuppression. Lancet. 2020;395(10229):1033-4.

10. Spezzani V, Piunno A, Iselin HU. Benign COVID-19 in an immunocompromised cancer patient - the case of a married couple. Swiss Med Wkly. 2020;150:w20246.

\section{Publisher's Note}

Springer Nature remains neutral with regard to jurisdictional claims in published maps and institutional affiliations.

Ready to submit your research? Choose BMC and benefit from:

- fast, convenient online submission

- thorough peer review by experienced researchers in your field

- rapid publication on acceptance

- support for research data, including large and complex data types

- gold Open Access which fosters wider collaboration and increased citations

- maximum visibility for your research: over $100 \mathrm{M}$ website views per year

At $\mathrm{BMC}$, research is always in progress.

Learn more biomedcentral.com/submissions 